\title{
Basophil activation test as a biomarker in allergic patients to platins undergoing rapid desensitization
}

\author{
Pedro Giavina-Bianchi ${ }^{1,2^{*}}$, Matthieu Picard ${ }^{2}$, Joana Caiado ${ }^{2}$, Mariana Castells ${ }^{2}$ \\ From 3rd WAO International Scientific Conference (WISC) 2014 \\ Rio de Janeiro, Brazil. 6-9 December 2014
}

\section{Background}

Rapid Drug Desensitization (RDD) has become a cornerstone of the management of immediate hypersensitivity reactions (HSRs) to chemotherapeutic agents, including biologicals. It is the only effective procedure for overcoming HSRs to first-line therapy, thus representing an important advance in patients' treatment and prognosis. Biomarkers to assess drug sensitization and monitor RDD safety and efficacy are lacking. Preliminary data suggested that in addition to skin testing, basophil activation test (BAT) could be used to assess patient's IgE sensitization to platins and provide markers of activation to evaluate the response to RDD.

\section{Methods}

We studied 12 patients with gastrointestinal and OBGYN cancers who presented hypersensitivity reactions to platins and 6 healthy volunteers who had never been exposed to platins. Skin testing and BAT were done before RDD to platins, and the expression of activation markers CD203c and CD63 was evaluated on basophils (HLADR-/CD41-/CD123+). Most patients were evaluated during 2 or more RDD procedures.

\section{Results}

BAT was positive in $9 / 12$ patients $(75 \%)$, with increased expression of CD203c (9 patients) and CD63 (4 patients). The BAT positivity was $66,7 \%$ (6/9) for carboplatin and $100 \%(3 / 3)$ for oxaliplatin. Subsequent BAT analysis in different RDD procedures showed that the test remained positive before each procedure with an even greater expression of CD203c and CD63, indicating temporary tolerance during RDD, which was lost after each exposure. In an attempt to correlate reactions during RDD with specific BAT markers, we observed an association

${ }^{1}$ University of São Paulo, Brazil

Full list of author information is available at the end of the article between CD63 expression and the severity of the reactions. All controls had negative tests. Further studies are needed to determine the predictive values of BAT in patients with platins hypersensitivity.

\section{Conclusions}

We standardized a BAT to platins with good sensitivity and which can predict patients with severe reactions during RDD. RDD to platinum drugs does not induce persistent hyporresponsiveness on basophils, highlighting the need to maintain repeated RDD in allergic patients to platins.

\section{Authors' details \\ 'University of São Paulo, Brazil. 'Brigham and Women's Hospital, Harvard Medical School, USA.}

Published: 8 April 2015

doi:10.1186/1939-4551-8-S1-A147

Cite this article as: Giavina-Bianchi et al:: Basophil activation test as a biomarker in allergic patients to platins undergoing rapid desensitization. World Allergy Organization Journal 2015 8(Suppl 1):A147.

Submit your next manuscript to BioMed Central and take full advantage of:

- Convenient online submission

- Thorough peer review

- No space constraints or color figure charges

- Immediate publication on acceptance

- Inclusion in PubMed, CAS, Scopus and Google Scholar

- Research which is freely available for redistribution 